\title{
Sobre o Dicionario de afixos do galego medieval
}

\author{
Xoán López Viñas \\ Universidade da Coruña
}

\begin{abstract}
Resumo:
Neste artigo presentamos unha versión parcial e provisoria do Dicionario de afixos do galego medieval, que constitúe o primeiro repertorio temático de formacións afixais derivativas dentro do sistema lingüístico galego-portugués e que está en fase de elaboración. O corpus textual en que nos baseamos cínxese, polo momento, á produción literaria do galego medieval, isto é, á poesía profana e relixiosa, á Arte de Trovar, ao Livro de Tristan, á Crónica Troiana, aos Miragres de Santiago e á Crónica de Santa Maria de Íria.

Canto á organización da información deste traballo, após a descrición da creación deste dicionario e do seu proceso de elaboración, detallamos a macroestrutura e a microestrutura dos artigos lexicográficos, cunha breve mostra de voces afixadas que aparecerán neste catálogo lexical.
\end{abstract}

\section{Palabras chave:}

Afixos, dicionario, formación de palabras, galego medieval, Lexicografía, Lingüística histórica.

\begin{abstract}
:
In this paper, we present a partial and provisional version of the Dicionario de afixos do galego medieval, which is the first thematic index of affixal derivative forms in the GalicianPortuguese linguistic system and which is in preparation. Up to now, the textual corpus we use covers the Galician medieval literary production, that is to say, secular and religious poetry, the Arte de Trovar, the Livro de Tristan, the Crónica Troiana, the Miragres de Santiago and the Crónica de Santa Maria de Íria.

The organization of the information in this work, after the description of the creation of the dictionary and its process, details the macrostructure and microstructure of lexicographical articles, with examples of affixed voices that will appear in this lexical index.
\end{abstract}

\section{Key words:}

Affixes, dictionary, word formation, mediaeval Galician, lexicography, historical grammar.

1 A elaboración deste Dicionario desenvólvese no marco do proxecto de investigación Glosario crítico da poesía medieval galego-portuguesa. I. Cantigas de amor e cantigas de amigo (ref. FFI2009-08917) [2010-2012], financiado polo Ministerio de Ciencia y Tecnología. Dirección General de Investigación. Subdirección General de Proyectos de Investigación. Poden consultarse as liñas xerais e o proceso de elaboración do proxecto en Ferreiro (2010). 


\section{Introdución}

Neste artigo pretendemos realizar unha achega inicial sobre o proceso de elaboración e a estrutura do Dicionario de afixos do galego medieval (en adiante $D A G M$ ), que estamos a elaborar e que se acha na súa fase final de execución. Neste sentido, esperamos poder ofrecer proximamente o resultado deste catálogo de voces afixadas, o cal aínda o estamos a completar e a lle realizar alteracións na configuración terminal deste dicionario, así como eventuais ampliacións da masa textual.

A idea de creación do $D A G M$ ten como punto de partida a análise e posterior sistematización dos datos extraídos do corpus que estabelecemos na Tese de Doutoramento en curso, titulada A formación de palabras no galego medieval: a afixación. Deste modo, xulgamos que sería moi interesante dispor todos estes vocábulos afixados nun repertorio léxico dicionarizado co fin de obtermos un maior aproveitamento e unha maior practicidade do noso traballo, para alén de o transferir máis rapidamente á sociedade.

Así pois, téndomos este marco como pano de fondo, comezamos a elaborar o $D A G M$, que conforma o primeiro dicionario temático contextualizado de afixos derivativos e das súas correspondentes voces afixadas no galego medieval. Non se trata, xa que logo, dun dicionario ao uso nin tampouco dun dicionario inverso (cfr. Martínez de Sousa 1995, Guerrero Salazar 2001/2002, Porto Dapena 2002), pois non listamos os vocábulos segundo a súa terminación, senón que só incluímos as palabras afixadas ordenadas alfabeticamente conforme o seu afixo correspondente -previamente definido etimolóxica, morfosintáctica e semanticamente- En certo modo, podería considerarse un dicionario de especialidade, mais esta denominación non parece ser moi acaída, xa que remite para as linguaxes especializadas ou de especialidade ${ }^{2}$.

En consecuencia, o $D A G M$ constitúe unha novidade nos estudos lexicográficos galego(-portuguese)s -e inclusive nos estudos hispánicos, salvo erro- ao non existir ningún manual lexicográfico deste tipo, quer da fase actual quer doutra(s) anterior(es). Cómpre recordar, ao respecto, que nos dicionarios galegos actuais os afixos derivativos se encontran no máximo incorporados asistematicamente no lemario dalgúns deles. Así, nos dicionarios DLG (1995), DGII (2004), GDCLG (2004), GDS21LG(2005), DXL (2005) e GDXL (2009) unicamente aparecen reunidos os prefixos, salvo en $D X L$ e $G D X L$ en que tamén se recolle o sufixo -mente.

2 Sobre os dicionarios especializados, consúltense as características e o proceso de elaboración en Cabré (1992). A respecto das diverxencias na denominación "lingua" / "linguaxe" e "especializado" / "de especialidade", véxase Lerat (1997). 
Por outra parte, tamén convén salientarmos que non contamos cun catálogo léxico íntegro de toda a produción medieval -global ou por xéneros-, xa que unicamente se reducen aos glosarios líricos de Michaëlis de Vasconcelos (1904), de Nunes (1972) e das edicións críticas de trobadores canto á lírica profana ${ }^{3}$; ao glosario de Mettmann (1972) para a poesía mariana; e aos glosarios de Magne (1944) e Lorenzo (1977) relativos á prosa (non notarial). Con todo, é de xustiza indicarmos tamén a existencia do Tesouro Medieval Informatizado da Lingua Galega (1993-), que, malia non constituír stricto sensu un dicionario -pois trátase dunha base de datos-, fornece unha importante información lingüística.

A este panorama debemos acrecentar a ausencia dun dicionario histórico e etimolóxico galego completo ${ }^{4}$, feito que impide aos/ás filólogos/as e aos/ás pesquisadores/as en xeral obteren datos máis concretos sobre a orixe, cronoloxía, formación e transmisión das voces do léxico galego, para alén das atestacións en corpus. Esta carencia sorprendente, se ben comprensíbel polo carácter serodio da nosa tradición gramatical (cfr. Sánchez Rei 2005: 93-121) e pola falta dunha edición íntegra dos manuscritos medievais, xustifica a necesidade urxente da construción deste dicionario coa finalidade de avanzarmos no coñecemento da nosa historia lingüística. Así mesmo, cumpriría incorporar estas e outras formas lingüísticas a un esperábel dicionario galego-portugués medieval e xeral, en que se complete a información contida nos dous dicionarios etimolóxicos portugueses existentes (DELP e DENFLP) coas análises da produción escrita en territorio galego.

Así as cousas, e antes de describirmos a macro e microestrutura do $D A G M$, é preciso referirmos brevemente unhas consideracións sobre o corpus textual en que nos estamos a basear para a elaboración do dicionario. Desta maneira, os textos que manexamos -polo momento- representan grosso modo entre o 15 e o $20 \%$ da produción total do período medieval, que consta de máis de 16000 unidades textuais ${ }^{5}$, repartidas en 82 obras, segundo os datos que extraemos do corpus do proxecto TMILG (1993-) e que podemos visualizar na seguinte gráfica:

3 Entre outras edicións críticas, salientamos as de Lanciani (1977), Finazzi-Agrò (1979), Simões (1991), Ferreiro (1992), Martínez Pereiro (1992), Tavani (1992), Arbor Aldea (2001), Tato Fontaíña (2007), Lorenzo Gradín (2008) e Lorenzo Gradín / Marcerano (2011).

4 Esta eiva está a ser reparada polo Instituto da Lingua Galega (ILG) coa elaboración do Dicionario Histórico da Lingua Galega e co Dicionario Medieval do Galego-Portugués, aínda que felizmente nesta (longa) espera podemos recorrer aos citados dicionarios etimolóxicos para o portugués.

5 De acordo cos responsábeis de sección do TMILG (Paulo Martínez Lema e Ricardo Pichel Gotérrez, a quen agradecemos esta información), unha "unidade textual" correspóndese con unha cantiga (no caso da lírica), un capítulo (para a prosa non notarial) ou un documento (no caso da prosa notarial). Esta etiqueta de "unidade textual" parece algo discutíbel, xa que hai capítulos na prosa literaria que ultrapasan con amplitude o que "mide" unha cantiga; en calquera caso, permite deseñar un mapa porcentual dos diferentes tipos de produción galega medieval. 


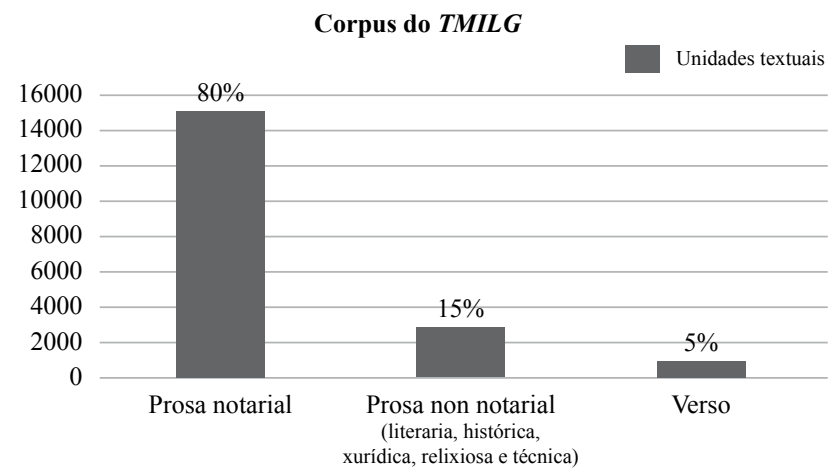

Gráfica 1 Corpus do TMILG segundo a tipoloxía textual. Datos extraídos de Pichel / Varela Barreiro (2009) e Martínez Lema (2008).

Relativamente ao noso corpus, este áchase delimitado ao galego literario medieval, de modo que se engloban toda a poesía orixinal ou de creación propia, tanto profana como relixiosa, excepto a Escola galego-castelá (1350 a 1450) por seren poemas deturpados a nivel lingüístico; a prosa literaria traducida, elaborada en territorio galego; e a prosa técnica orixinal, en que unicamente se insire un texto. En consecuencia, fican, inicialmente, ausentes desta versión a prosa histórica, a xurídica e a notarial, por seren obras demasiado fragmentarias e/ou con edicións deficientes ou pouco fiábeis na súa maioría. Con todo, é moi probábel que se incorporen coa maior brevidade posíbel, inclusive nesta primeira versión.

Por tanto, as sete obras do noso corpus (se considerarmos a lírica profana como un único volume), que se corresponden con 2754 unidades textuais, adoitan clasificarse en cinco grandes ámbitos, conforme o xénero:

1. Lírica profana (LP): Cantigas d'amigo, Cantigas d'amor, Cantigas d'escarnho e malizer e xéneros menores.

2. Lírica relixiosa: Cantigas de Santa María (CSM).

3. Prosa literaria: Livro de Tristán (LT) e Crónica Troiana $(C T)$.

4. Prosa relixiosa: Miragres de Santiago (MS) e Crónica de Santa María de Iria $(C S M I)$.

5. Prosa técnica: Arte de Trovar (AT). 


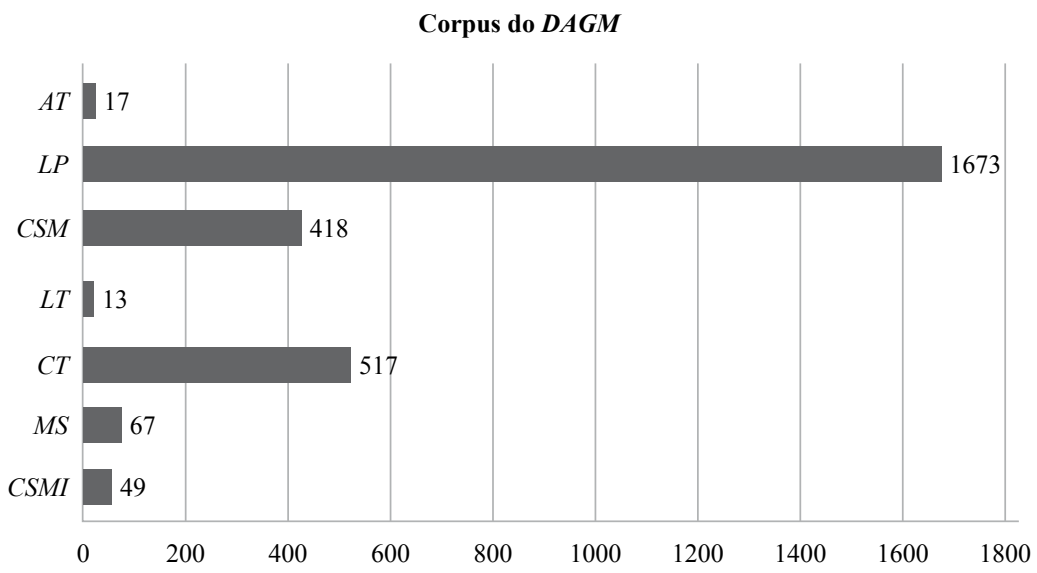

Gráfica 2 Obras que conforman o corpus do $D A G M$, segundo o número de unidades textuais.

\section{Elaboración e descrición do Dicionario de afixos do galego medieval}

Após o estabelecemento do corpus de traballo, procedemos ao tratamento exhaustivo dos datos lingüísticos obtidos a partir das sete obras medievais. Este proceso de elaboración do traballo constou de diversas fases interrelacionadas:

1. En primeiro lugar, realizamos a colecta dos datos. Esta etapa articulouse en dous momentos, como a extracción verbo pro verbo de todas aquelas palabras complexas que presentaban afixos derivativos e que eran candidatas a formaren parte deste vocabulario analítico, así como o agrupamento das variantes gráficas.

2. A seguir, identificamos as voces afixadas de formación galego-portuguesa, segundo os datos que fornecen os diferentes dicionarios histórico-etimolóxicos da lingua portuguesa (DENFLP 1986, DELP 1977, DHLP 2001), da latina (OLD 1968), da francesa (TLFi 2005) e da española (DCECH 1980-1991), para alén das etimoloxías suxeridas por Lorenzo (1977) e por Ferreiro $(1997)^{6}$. A este respecto, é preciso remarcar que non estamos a afirmar que os vocábulos de procedencia latina -do tipo diferença < DIFFERĔNTǏA- non

6 Alén disto, para o significado e rexistro dalgúns medievalismos que non se recollían nestes dicionarios tamén consultamos Barreiro García (1985, 1995), Cejador y Frauja (1929). 
pertencen ao sistema lingüístico galego-portugués, senón que unicamente recollemos neste dicionario aquelas voces que os diferentes etimólogos clasifican como "formacións romances", cal en acordança (< acordar $+-n c ̧ a)$, en mandado $(<$ mandar $+-a d o)$ etc. Este confronto dicionarístico tivo como finalidade asegurarmos a presenza do proceso derivativo en cada palabra, alén de confirmarmos o étimo das bases e dos sufixos, xa que existen discrepancias entre as diferentes propostas etimolóxicas, optando neses casos por un criterio de coincidencia maioritaria.

3. En terceiro lugar, levamos a cabo a análise lingüística das unidades lexicais, que abranxeu a abonación, a clasificación gramatical do derivado e da base, a determinación dos significados, a produtividade e a futura inclusión de todos estes datos no $D A G M$. Así, as primeiras dificultades que se presentaron afectan á decisión de agrupar as diversas variantes baixo un único lema ou discriminalas en diferentes entradas. Estas duplicidades atinxen tamén ao estabelecemento do lema ou entrada, debido á existencia de variantes lingüísticas no corpus, así como á disposición da información morfolóxica, sintáctica e semántica no interior de cada entrada. Alén disto, do punto de vista semántico, foron numerosos os problemas á volta da pormenorización das acepcións semánticas, de maneira que aínda non puidemos levar a cabo unha afinación definitiva destas.

Por outra parte, convén aclararmos nesta epígrafe que para a análise da produtividade non tivemos en conta o número de ocorrencias de cada palabra, senón o número de ocorrencias de cada sufixo sobre unha base lexical diferente, xa que o primeiro significaría reducir o concepto da produtividade ao de frecuencia e, en consecuencia, falsear a análise real. En síntese, os datos tratados son nomeadamente ocorrencias das unidades rexistradas e analizadas en córpora textuais.

Nos seguintes apartados describimos en profundidade o corpo do dicionario, isto é, a estrutura interna e externa do $D A G M$ e comentamos aquelas dificultades máis relevantes levantadas no proceso de elaboración.

\subsection{Corpo do dicionario: macroestrutura e microestrutura dos artigos lexicográficos}

Denomínase corpo do dicionario o lugar onde se relaciona o conxunto de artigos

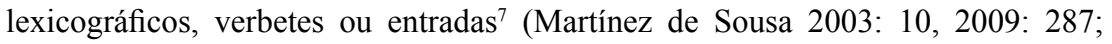

7 A respecto desta última denominación, cfr. a n. 11 en que expomos os diversos significados que a palabra "entrada" presenta e advertimos do uso que facemos desta. 
Haensch 1982: 459); neste apartado proporciónase toda a información sobre a unidade léxica ou gramatical de que se tratar e varía en función da finalidade ou tipo de dicionario, do destinatario, da intención do autor, da extensión da obra etc. Cada artigo lexicográfico está formado por unha unidade lingüística que constitúe o lema e por un conxunto de informacións ordenadas que o suceden (Martínez de Sousa 2003: 10, 17; 2009: 101, 123). Estas dúas partes reciben os nomes de macroestrutura e microestrutura, respectivamente, termos propostos orixinalmente pola lexicógrafa Rey-Debove (1971: 21). A investigadora francesa entende por macroestrutura o conxunto de entradas ordenadas segundo a progresión vertical do dicionario e que veñen representadas polo lema, entrada ou voz. Este lema actúa tanto no nivel externo do corpo do dicionario, isto é, na ordenación das voces, canto no nivel interno, como cabeza de entrada ou palabra que abre e precede a microestrutura. Porén, posteriormente o lexicógrafo alemán Haensch (1982: 452) estendeu o significado de macroestrutura á estrutura global do dicionario, ou sexa, á parte introdutoria, ao corpo do dicionario en que se dispoñen os artigos e aos anexos.

No tocante á a microestrutura, tamén existen dúas posturas encontradas. Así, para Rey-Debove (1971) trátase do conxunto de informacións ordenadas que no artigo lexicográfico seguen á entrada, de modo que afecta ao artigo como unidade de estruturación e descrición lingüística, e cuxa lectura é horizontal. En troca, Haensch (1982: 461-479) argumenta que a microestrutura se refire ao conxunto de artigos ou entradas, que se compoñen dun lema e dunha parte definitoria (etimoloxía, pronuncia, grafía, indicacións gramaticais, acepcións mediante definicións etc.).

Por tanto, na literatura especializada actual non existe unanimidade sobre a delimitación ou normalización ${ }^{8}$ do concepto de macroestrutura e de microestrutura -aínda que a maior parte dos estudos debaten fundamentalmente sobre a noción de macroestrutura-, de xeito que uns optan pola hipótese francesa (Martínez de Sousa 2003: 10 e 17, 2009: 101 e 123; Porto Dapena 2002: 135-136), en canto outros se decantan pola alemá (Barros 2004, Krieger / Finatto 2004) ${ }^{9}$.

8 Utilizamos "normalización" co sentido de "normalización terminolóxica" (Cabré 1992: 417), que alude á actividade encargada de "fijar las denominaciones y sus correspondientes definiciones o explicaciones con objeto de hacer posible una comunicación que no dé lugar a confusiones como consecuencia de la univocidad de sus términos, teniendo en cuenta el principio de economía del lenguaje" (Irazazábal / Andrés / Ferrándiz 1997: 2). Este termo tamén se coñece co nome de estandarización (ing. standardization; cfr. neste sentido as normas ISO [International Organization for Standardization]), aínda que para Cabré (1992: 409) son conceptos diferentes.

9 Para profundar máis na falta de consenso sobre o concepto de macroestrutura, véxase Bugueño Miranda (2007). Por outra parte, non debe confundirse coa denominación macroestrutura (textual), 
Pola nosa parte, secundamos a teoría de Haensch cunha leve discrepancia. Estimamos que macroestrutura debe reservarse unicamente para a maneira en que se organizan os artigos lexicográficos, cuxa ordenación ten como referente principal o lema, e, por consecuencia, non temos en conta as introducións nin os anexos. No entanto, con microestrutura designamos as partes en que se divide o artigo lexicográfico: lema, categoría gramatical, acepcións, contextos ou abonacións etc.

\subsubsection{Macroestrutura dos artigos lexicográficos}

Canto á organización externa dos artigos lexicográficos do dicionario, isto é, canto á macroestrutura, adoptamos un criterio alfabético ${ }^{10}$ reitor tanto na ordenación de todos os afixos como na disposición interna de cada un destes. No caso dos sufixos, cómpre precisar que estes foron colocados conforme a determinación mórfica de cada sufixo, é dicir, desprovistos daqueles elementos -como, por exemplo, da vogal temática- que foren susceptíbeis de alomorfía.

Noutra orde de cousas, do punto de vista tipográfico, todos os artigos aparecen distribuídos en dúas columnas por páxina, como acostuma ser o máis habitual nos dicionarios en papel (Martínez de Sousa 2003: 14, 2009: 275).

\subsubsection{Microestrutura dos artigos lexicográficos}

$\mathrm{Na}$ microestrutura especificamos toda a información que se inclúe en cada artigo lexicográfico ou verbete e que xira en torno á unidade léxica inicial. En cada artigo descritivo, a información incluída articúlase consoante catro apartados:

\section{Entrada.}

2. Aparato de variantes.

3. Datación cronolóxica.

4. Remisións.

creada polo lingüista holandés Van Dijk (1977) (cfr. tamén López Viñas / Lourenço Módia / Moreda Leirado 2011: 542-543), que se refire á estrutura semántica do conxunto do texto.

10 Este é o criterio básico e común de ordenación dos artigos na maior parte dos dicionarios, mais existen outros criterios como o ideográfico, o etimolóxico, o estatístico etc. (cfr. Haensch 1982: 452-457; Porto Dapena 2002: 178-181). 


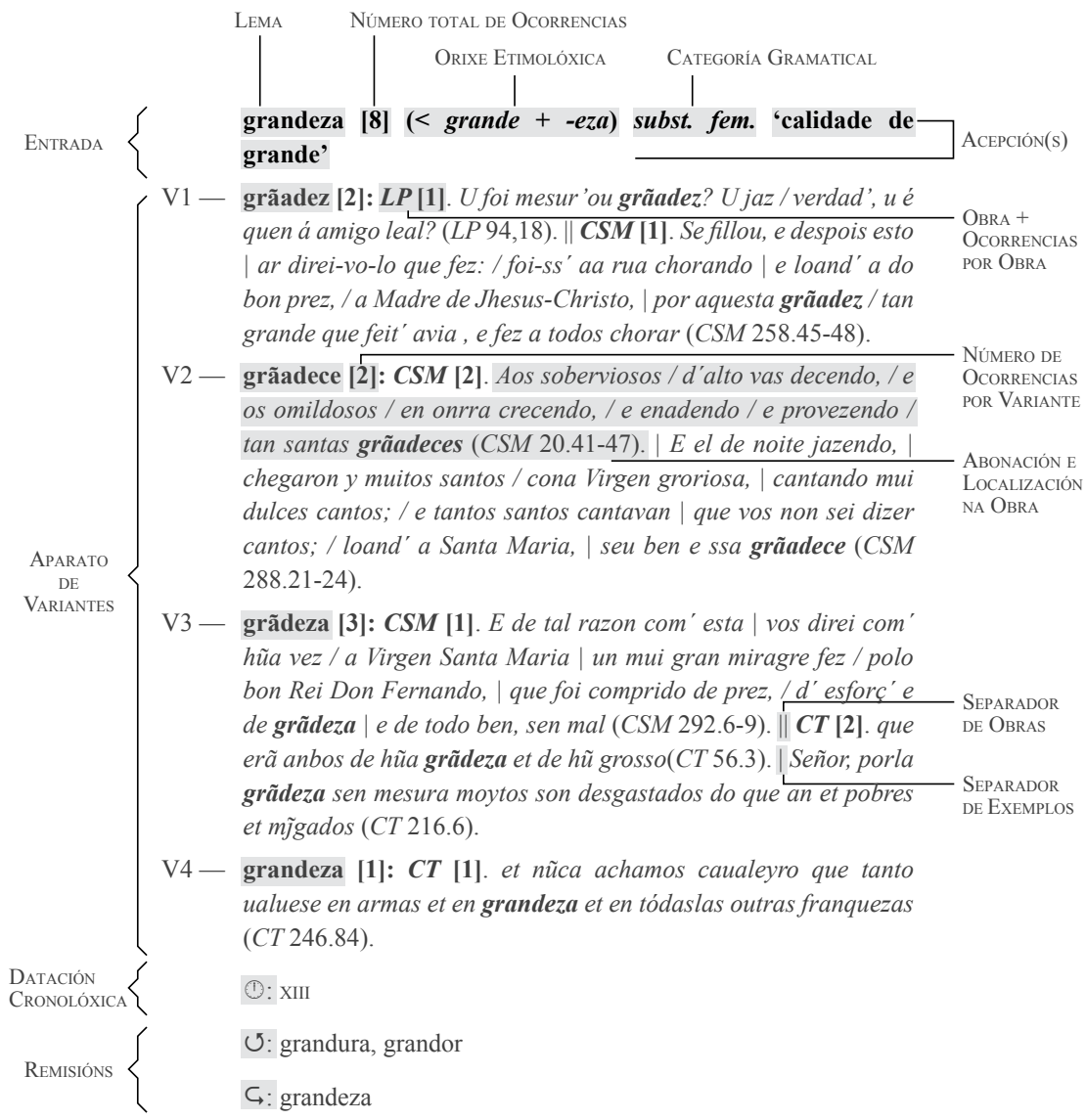

\subsubsection{Entrada}

A entrada ${ }^{11}$, disposta tipograficamente en cor negra grosa para destacar o lemario, está orientada a fornecer de forma resumida as informacións lingüísticas máis

11 Os manuais de Lexicografia consideran que "entrada" pode facer referencia quer ao lema quer ao artigo lexicográfico en si, polo que existe certa confusión á volta desta palabra. A este respecto, véxase Martínez de Sousa (1995: 180-181, s.v. entrada; 2003: 101-104 e 123-124) e Porto Dapena (2002: 136 e 182-185) que reflexionan acerca da polisemia e controversia da denominación "entrada" (calco do inglés entry). Neste sentido, cómpre advertirmos que, como non é un dicionario xeral, facemos un uso semántico ampliado do vocábulo "entrada", pois utilizámolo para nos referirmos ao enunciado da información lingüística principal de cada artigo e non só ao lema (cfr. Varela Barreiro (2010), que propón a denominación “cabezallo"). 
importantes. Na súa versión máis extensa, a entrada componse dos seguintes elementos:
a) lema principal,
b) número total de ocorrencias,
c) orixe etimolóxica,
d) categoría gramatical,
e) información semántica.

a) O lema, cabeza de verbete ou entrada, é a unidade (neste caso, palabra derivada por afixación) sobre a que versa todo o artigo lexicográfico e vén resaltado tipograficamente en letra minúscula negra grosa de tipo redondo. Para o estabelecemento do lema optamos por utilizar os criterios morfolóxicos máis habituais nos dicionarios e tamén o criterio estatístico para a determinación gráfica con base no corpus medieval.

Así, os nomes substantivos sen oposición de xénero lematízanse ${ }^{12}$ no masculino singular ou no feminino singular coa grafía máis frecuente. Este mesmo lematizado é o que seguen os nomes adxectivos de unha terminación, ao presentaren unha única forma sincrética para masculino e feminino. Canto aos substantivos con oposición xenérica baseada en diferenzas de sexo e aos adxectivos de dúas terminacións, indícase a forma masculina singular seguida da feminina, representada neste caso mediante a terminación final da palabra precedida de trazo curto $(-a)$. Polo que se refire aos verbos, estes incorpóranse segundo o infinitivo do verbo correspondente, acompañado do pronome persoal átono se cando constituír un verbo pronominal. Finalmente, no tocante aos adverbios, por seren invariábeis, transcríbense tal e como aparecen, a contemplarmos a frecuencia gráfica.

12 A lematización consiste en representar todas as posibilidades flexivas dunha palabra mediante unha mesma "forma de citación" (Lyons 1980: 20) ou lema. Unha definición máis desenvolvida achámola no Dicionário de Termos Linguísticos (Xavier / Mateus 1990/1992, s.v. lematização) en que se contempla a lematización como o "reagrupamento sob uma forma gráfica representativa de todas as formas que pode apresentar uma mesma unidade de significação lexicográfica (tradicionalmente, palavra simples ou complexa)". Porén, algúns autores alargan o sentido deste termo; así, Iriarte Sanromán (2001: 2021) entende por lematización "o acto de registrar (no sentido de consignar, catalogar ou inventariar), sob a entrada, lema ou vedeta que encabeça o artigo do dicionário (ou sob uma sub-entrada ou sublema), diferentes tipos de unidades lexicográficas de uma língua, de preferência extraídas de um corpus". 
gornimento [15] (< gornir + -mento) subst. masc. 'adorno, vestido'; 'socorro, axuda'

mandado [144] $(<$ mandar + -ado) subst. masc. 'orde, mandato, recado', 'aquilo que se lle manda facer a alguén'

honra [53] (< honrar) subst. fem. 'sentimento do deber, distinción, graza, virtude, dignidade'

maravilhoso -a [14] (< maravilha + -oso/a) adx. 'extraordinario, sobrenatural; admirábel, que provoca grande admiración'

apoderar [8] $(<a-+$ poder $+-a r) v b o$. 'tomar pose ou dominio, conquistar'

regeamente $[4](<$ régea +- mente $) a d v$. 'fortemente'

b) A seguir, cuantificamos o número total de ocorrencias gráficas (tokens) dunha mesma palabra do noso corpus textual. Este número confrontarase, no estudo relativo a cada un dos prefixos e dos sufixos, coa cifra de palabras lingüística ou gramaticalmente diferentes (types) ${ }^{13}$.

c) En cuarto lugar, especificamos a orixe etimolóxica da palabra derivada. Neste último aspecto cinxímonos a indicar o étimo máis común a nos basearmos nos dicionarios etimolóxicos consultados que xa especificamos no apartado anterior; naqueles casos en que existiren diversas propostas de orixe, seleccionamos a opción maioritaria ou a que consideramos máis acertada, xa que existen diverxencias varias.

d) No apartado dedicado á categoría gramatical, sinalamos en letra itálica mediante o uso das abreviaturas habituais a categoría gramatical (substantivo, adxectivo, verbo ou adverbio) $)^{14}$ e deseguido o xénero no substantivo e a caracterización sintáctica no verbo (transitivo, pronominal...). Neste ítem debemos salientar o feito de incluírmos no glosario os adverbios acabados en -mente, circunstancia que non se produce nos dicionarios xerais e raramente se especifica noutros repertorios léxicos, como no $D D G M$ (2006) ou no glosario mariano de Mettmann (1972).

13 A diferenciación entre tokens e types procede de Peirce (1931-1958).

14 A terminoloxía para clasificarmos as diferentes categorías de palabras é a empregada en López Viñas / Lourenço Módia / Moreda Leirado (2011), que está baseada, con certas mudanzas, en Freixeiro Mato (2000) e Costa Casas / González Refoxo / Morán Fraga / Rábade Castiñeira (1988). 
e) Finalmente, na acepcións reúnense os diferentes significados que se encontran no corpus. A acepción é o significado en que se toma unha unidade léxica (Martínez de Sousa 2009: 184). Este significado exprésase mediante unha definición (lexicográfica), que na maioría dos casos optamos ora por unha definición sinonímica, en que se remite a outra unidade ou a outras da mesma categoría gramatical e de igual significado (Martínez de Sousa 2009: 159), ora por unha definición intensional. Para a enunciación destas definicións imos ter en conta as elaboradas, con leves modificacións puntuais, nos diversos glosarios existentes, como o de Mettmann (1972) ou de Michaëlis de Vasconcelos (1920), entre outros.

Por outra parte, e como xa argüímos no inicio deste artigo, no estado actual do $D A G M$ non discriminamos as acepcións que as diferentes palabras afixadas presentaren, porque isto implicaría un maior esforzo -que retrasaría a nosa tese de doutoramento-, que esperamos levar a cabo en próximas fases. Así mesmo, é necesario subliñar que tampouco realizamos un labor tan minucioso e profundo como, por exemplo, o que describe Varela Barreiro (2010) para a construción dun novo glosario do Cancioneiro da Ajuda, a partir da lectura crítica (e inédita) estabelecida por Mariña Arbor Aldea.

verbete (principal) [X = número total de ocorrencias] (< orixe etimolóxica) categoría gramatical 'información semántica'

gornimento [15] (< gornir + -mento) subst. masc. 'adorno, vestido'; 'socorro, axuda'

\subsubsection{Aparato de variantes}

No parágrafo seguinte colocamos o aparato de variantes gráficas do lema contextualizadas nos diferentes textos do noso corpus. Esta sección articúlase conforme os seguintes parámetros secuenciais:

a) variante gráfica ${ }^{1,2,3 \ldots}$,

b) número total de ocorrencias (por variante), conforme as obras en que se documenta,

c) sigla da(s) obra(s) en que se rexistra, 
d) número parcial de ocorrencias (por obra),

e) abonación(s) e localización na obra.

a) Canto ás diferentes variantes gráficas, estas aparecen separadas en alíneas diferentes e ordenadas alfabeticamente. A decisión de manter esta diverxencia gráfica sen distribución grafemática para un mesmo fonema radica no feito de estas poderen ter unha utilidade para outros estudos tanxenciais e por preferirmos conservar os datos tal e como aparecen reflectidos nas edicións, xa que en moitos casos é posíbel estarmos perante abreviacións mal desenvoltas, palabras mal segmentadas -sobre todo no caso da lírica- etc. que poderían alterar o significado e/ou a veracidade dos datos lingüísticos.

Por outro lado, é preciso lembrar que as palabras rexistradas cos dous xéneros e/ou cos dous números non son susceptíbeis de conformaren dúas variantes morfolóxicas, ou lemas secundarios, senón que se engloban nunha única que se corresponde co lema designado.

b) Os seguintes elementos que se citan son o número total de ocorrencias por variante, a sigla da obra, as ocorrencias por obra e, finalmente, a abonación, isto é, a contextualización da voz sufixada nun fragmento de texto e a súa localización (sigla, número do capítulo e liña) na obra. Este excerto normalmente ten como unidade de medida o enunciado que vai desde o punto anterior até o seguinte. Nesta versión estamos a incorporar exhaustivamente todas as veces en que aparece cada termo sufixado, mais é probábel que posteriormente fagamos unha selección das citas textuais máis interesantes debido á vasta extensión do Dicionario.

variante $^{1,2 \ldots}[\mathbf{X}]$ (= total de ocorrencias por variante). SIGLA $[\mathbf{X}]$ (= ocorrencias por obra): contexto (localización da obra).

atreuemento [1]. CT [1]. ¿Et cõmo fuste ousado ou per cujo cõssello ou quen te mãdou que tã grande atreuemento fezesses et tã grã sandiçe? (CT 23.15-16).

atrevemento [1]: CSM [1]. Gran dereit' é que fill' o demo por escarmento / quen contra Santa Maria filla atrevemento (CSM 34.3-4).

atreviment' [2]. LP [2]. Eu que a amo mais ca min, / fig' est' atreviment' al / $u$ lhi dixe este meu mal; / mais pero, pois me d'ela vin, / nulh'omen non lh'ar disse ren / senon con que lhi fosse ben (LP 47,14). | Eu que a amo mais ca min, / fig'est'atreviment'al / $u$ lhi dixe este meu mal (LP 47,14). 


\subsubsection{Datación cronolóxica}

Nun terceiro caso, indicamos a data da primeira aparición nos textos existentes, que se corrobora coa que indican os dicionarios etimolóxicos portugueses, aos cales en certas ocasións puidemos adiantar a data, e tamén os glosarios galegos. Neste sentido, o $D A G M$ tamén constitúe unha fonte de retroalimentación na atestación do léxico galego-portugués.

(1) (= data da primeira aparición testemuñal en corpus textual)

(1): s. XIII (entendimento).

\subsubsection{Remisións}

No cuarto e último bloque indícase, por un lado, a relación con outros termos afixais que se rexistran no texto, mediante o símbolo $\langle\mathcal{U}\rangle$, e cos que probabelmente estean en rivalidade ou alternancia; por exemplo: abastamento debe relacionarse con basteçemento e bastimento.

Por outro lado, e noutra alínea introducida polo símbolo $\langle\varsigma>$, remítese para o "resultado actual" ou verbete moderno estándar, en canto outras veces fai referencia ao vocábulo por que foi substituído, neste caso indicado entre corchetes e cunha frecha $[\rightarrow]$.

$$
\begin{aligned}
& \text { U: 'relaciónese con'. } \\
& \text { С: 'resultado actual'. } \\
& \text { U: traslado } \\
& \text { С: }[\rightarrow \text { translación (+lat.)] }
\end{aligned}
$$

\section{A modo de exemplo: o sufixo -çon}

Un dos sufixos máis característicos do galego-portugués é <-çon>, solución derivada da forma latina -TǏōNE, a cal era froito da amálgama da desinencia de participio de pretérito -TU e mais o sufixo -ĪōNE (Ferreiro 1997: 140). Así pois, a seguir expomos un extracto do $D A G M$ en que se relacionan as palabras colectadas que presentan formacións sufixadas en galego-portugués co sufixo -çon, tal e como propoñen os dicionarios etimolóxicos referidos, con base no noso corpus de galego literario medieval. 
escantaçon [1] (< escantar + -çon) subst. fem. 'arte de bruxaría'

escantaçon [1]: LP [1]. e escanta ben per olh'e per calheiro / e ssabe muito bõa escantaçon ( $L P$ $43,4)$.

(1): XIII

U: encantaçon, encantamento, encanto

$\hookrightarrow:[\rightarrow$ encantamento (+lat.) $]$

estremaçon [1] (< estremer + -çon) subst. fem. 'distinción'

estremaçon [1]: CSM [1]. En ssa casa e amostrar a leer / a seu fill'e outrossi a escrever / com' el escrevia, que sol connocer / non podian nen fazer estremaçon (CSM 265.40-43).

(1): XIII

U: -

५: estremazón

perdoaçõ [1] (< perdoar + -çon) subst. fem. 'condición ou calidade do que é perdoábel' perdoaçõ [1]: $\boldsymbol{M S}$ [1]. et lle de soude do corpo et vida perdurauell da alma en Parayso et perdoaç̃ dos seus pecados quando d'este mũdo seyr (MS 17).

(1): XIII

U: perdon, perdoança, perdoamento

$\hookrightarrow$ : perdón

perseguiçon [2] (< perseguir + -çon) subst. fem. 'persecución'

perseguçon [1]: $\boldsymbol{C S M}$ [1]: E el aquesto dizendo, | pareceu-ll' a Groriosa / que alumẽou a carcer, | tan muito vẽo fremosa, / e disse-ll': "Oý ta coita | e non fui mui vagarosa / en vĩir pera livrar-te | daquesta perseguçon" (CSM 227.40-43).

perseguiçon [1]: CSMI [1]. Et tanto foi a perseguiçon et coita de fame que as madres matavan seus fillos et os comian con fame (CSMI II.2.2.11-12).

(1): XIII

U: perseguição, perseguimento

$\hookrightarrow:[\rightarrow$ persecución (+lat.)]

pregaçon [1] (< pregar + -çon) subst. fem. 'discurso relixioso'

preegaçõ [1]: $\boldsymbol{M S}$ [1]. et el fezoo pescador dos homes porque por la sua preegaçõ gaanou moytas almas para el (MS 209).
(1): XIII

U: prega

$\hookrightarrow$ : predicación, prédica

quitaçon [4] (< quitar + -çon) subst. fem. 'acto e/ ou efecto de quitar'

quitaçon [4]: LP [4]. [A] Cítola vi andar-se queixando / de que lhi non davan sas quitações (LP 18,6). | E por levá-la quitaçon dobrada/se [me] queixou; e catei u jazia / éno padron, e achei que avia / de todo ben sa quitaçon levada; / poren faz mal, que non pode peor; / mais tant'á el de quitaçon sabor (LP 18,6).

(1): XIII

U: quita, quitamento

५: quitación

trasladaçõ [5] (< trasladar + -çon) subst. fem. 'acto de trasladar'

trasladaçõ [3]: MS [3]. Ata aqui vos cõtamos da paixõ et trasladaçõ de Santiago Zebedeu et das batallas que fezo Calrros em España, et ora vos cõtaremos de Santiago Alffeu (MS 19). | Ata aqui

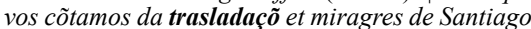
et des aqui endeante vos cõtaremos com̃o Calrros librou España do poderio dos mouros, segundo conta Dom Turpim, arçibispo de Reens (MS 69). | et chegou y ẽno dia que lle fazẽ a festa da trasladaç̃ (MS 212).

trelladaçon [2]: CSMI [2]. et desla passion de Jhesu Christo fasta a trelladaçon do corpo de Santiago foron onze anos, que foi tragido porlo mar en sete dias ao porto de Iria et sepultado en Conpostella en tenpo de Luparia, segundo se léé por sua leitura et porlo libro a que dizen "Calixto» (CSMI I.1.3.11-14). | Pero finalmente tanta foi a omilldade et santidade do obispo Dalmacio que o papa, et cardeaes et todo o concilio con grandes preces inpretrou o seguint privilegio da trasladaçon do obispado de Iria en Conpostella et de seeren exenptos os bispados dos bispos de Santiago; et esto con consello dos cardeaes et de trezentos et cinquoenta obispos que estaban enno concilio, o qual nunca seus predecessores poderan alcançar (CSMI V.5.4.22-27).

(1): XIII

$\checkmark:$ traslado

$\hookrightarrow:[\rightarrow$ translación (+lat.)]

\section{Cabo}

En síntese, foi a nosa intención nestas páxinas presentarmos brevemente o Dicionario de afixos do galego medieval, que conforma a primeira obra lexicográfica de afixos 
e voces afixadas da lingua galega, tanto a nivel actual como medieval, aínda que de momento só nos centramos nun corpus textual que engloba a produción literaria galega medieval.

Non obstante, como xa indicamos trátase dunha versión inacabada e, nalgúns aspectos, provisoria, pois adoptamos algunhas decisións máis ou menos definitivas, en canto outras están pendentes até concluír a nosa tese de doutoramento, como por exemplo a ampliación do corpus ou a pormenorización efectiva das acepcións semánticas. Así pois, esperamos poder ofrecer nun futuro próximo a versión final e máis completa posíbel deste Dicionario.

Por outra parte, e xa para concluír, alén de editarmos o DAGM en soporte papel, tamén esperamos poder ofrecer unha versión en sorporte dixital, tanto estática (en “.pdf”) como dinámica, en forma de aplicación informática en CD e, se callar, aloxada na páxina web do Grupo de Investigación Lingüística e Literaria Galega (ILLA) da UDC (www.illa.udc.es).

\section{Referencias bibliográficas}

Arbor Aldea, Mariña (2001): O cancioneiro de Don Afonso Sánchez. Edición e estudio (Santiago de Compostela: Universidade, Servicio de Publicacións e Intercambio Científico).

$A T=$ Tavani, Giuseppe (ed.) (2002) [1999]: Arte de Trovar do Cancioneiro da Biblioteca Nacional de Lisboa. Introdução, Edição crítica e Fac-símile (Lisboa: Edições Colibri).

Barreiro García, M. ${ }^{a}$ Carme (1985): O léxico dos Miragres de Santiago. Memoria de Licenciatura. Universidade de Santiago de Compostela.

Barreiro García, M. ${ }^{a}$ Carme (1995): A documentación notarial do concello de Noia (ss. XIV-XVI). Tese de Doutoramento. Universidade de Santiago de Compostela.

Barros, Lídia Almeida (2004): Curso Básico de Terminologia (São Paulo: Edusp).

Bugueño Miranda, Félix Valentín (2007): “O que é macroestrutura no dicionário de língua?”, en Isquerdo, Aparecida Negri / Alves, Ieda Maria (org.), As ciencias do léxico: lexicologia, lexicografia, terminologia. Vol. III, 261-272 (Campo Grande: Universidade Federal de Mato Grosso do Sul).

Cabré, M. Teresa (1992): La terminologia. La teoria, els mètodes, les aplicacions (Barcelona: Empúries). 
Cejador y Frauja, Julio (1929): Vocabulario medieval castellano (Madrid: Hernando).

Costa Casas, Xoán Xosé / González Refoxo, M. ${ }^{a}$ dos Anxos / Morán Fraga, César Carlos / Rábade Castiñeira, Xoán Carlos (1988): Nova gramática para a aprendizaxe da língua (A Coruña: Vía Láctea).

CSM = Mettmann, Walter (ed.) (1986-1988-1989): Cantigas de Santa María. I (Cantigas 1 a 100). II I (Cantigas 101 a 260). III I (Cantigas 261 a 427). Edición, introducción y notas de... (Madrid: Clásicos Castalia).

CSMI = Souto Cabo, José António (ed.) (1986) = Vasques, Rui: Crónica de Santa Maria de Íria. Estudo e edizón de José António Souto Cabo (Santiago: Cabido da S. A. M. I. Catedral de Santiago / Ediciós do Castro).

$C T=$ Lorenzo, Ramón (ed.) (1985): Crónica Troiana (A Coruña: Fundación Pedro Barrié de la Maza / RAG).

$D C E C H=$ Corominas, Joan / Pascual, José A. (1980-1991): Diccionario crítico etimológico castellano e hispánico. 6 volumes (Madrid: Gredos).

$D D G M=$ González Seoane, Ernesto Xosé (coord.) / Álvarez de la Granja, María / Boullón Agrelo, Ana Isabel (2006): Dicionario de dicionarios do galego medieval (Santiago de Compostela: Universidade de Santiago de Compostela).

DELP = Machado, José Pedro (1977³): Dicionário Etimológico Língua Portuguesa . 5 vols. (Lisboa: Livros Horizonte).

DENFLP = Cunha, Antônio Geraldo da $\left(1986^{2}\right)$ [1982]: Dicionário Etimológico Nova Fronteira da Língua Portuguesa (Rio de Janeiro: Editora Nova Fronteira).

$D G I$ = Ledo Cabido, Bieito (2004): Dicionario de galego (Vigo: Ir Indo).

DHLP = Houaiss, Antônio (2001): Dicionário Houaiss da Língua Portuguesa (Rio de Janeiro: Objetiva).

Dijk, Teun Adrianus van (1977): Text and context: Explorations in the semantics and pragmatics of discurse (London: Longman).

$D L G=$ Alonso Estravís, Isaac (1995): Dicionário da Língua Galega (Santiago de Compostela: Sotelo Blanco).

$D X L=$ Carballeira Anllo, Xosé M. ${ }^{\text {a }}$ (coord.) (2005): Dicionario Xerais da Lingua (Vigo: Xerais). 
Ferreiro, Manuel (ed.) (1992): As cantigas de Rodrigu'Eanes de Vasconcelos. Edición crítica con introdución, notas e glosário (Santiago de Compostela: Edicións Laiovento).

Ferreiro, Manuel (1997): Gramática histórica da lingua galega. II. Lexicoloxía (Santiago de Compostela: Edicións Laiovento). [2. ${ }^{\mathrm{a}}$ ed.: 2001].

Ferreiro, Manuel (2010): "Sobre o proxecto «Glosario crítico da lírica profana galego-portuguesa»”, en Brea, Mercedes / López Martínez-Morás, Santiago (eds.): Aproximacións ao estudo do Vocabulario trobadoresco, 239-252 (Santiago de Compostela: Centro Ramón Piñeiro para a Investigación en Humanidades).

Finazzi-Agrò, Ettore (1979): Il canzoniere di Johan Mendiz de Briteyros (L'Aquila: Japadre).

Freixeiro Mato, Xosé Ramón (2000): Gramática da lingua galega. II. Morfosintaxe (Vigo: A Nosa Terra).

GDCLG = Pena, Xosé Antonio (dir.) (2004): Gran Dicionario Cumio da Lingua Galega (Vigo: Edicións do Cumio)

GDS21LG = Pena, Xosé Antonio (dir.) (2005): Gran dicionario século 21 da lingua galega (Vigo: Galaxia / Do Cumio).

$G D X L=$ Carballeira Anllo, Xosé M. ${ }^{a}$ (coord.) (2009): Gran Dicionario Xerais da Lingua. Vol. I: A-G. Vol. II: H-Z (Vigo: Xerais).

Guerrero Salazar, Susana (2001/2002): "Los diccionarios inversos de la lengua española: descripción del repertorio bibliográfico", Revista de lexicografia 8, 269-295.

Haensch, Günther (1982): “Aspectos prácticos de la elaboración de diccionarios”, en Haensch, Günther / Wolf, Lothar / Ettinger, Stefan / Werner, Reinhold, La lexicografía: de la lingüística teórica a la lexicografía práctica, 395-534 (Madrid: Gredos).

Irazazábal Nerpell, Amelia de / Andrés y de Irazazábal, M. ${ }^{a}$ Isabel de / Ferrándiz, Susana (1997): Nazioarteko Terminologia Biltzarra / Congreso Internacional de Terminologia / Congrès International de Terminologie / International Congress on Terminology (Donostia, Gasteiz: UZEI / HAEE-IVAP). Tamén dispoñíbel en http://www.uzei.com/Modulos/UsuariosFtp/Conexion/archivos83A.pdf.

Iriarte Sanromán, Álvaro (2001): A Unidade Lexicográfica. Palavras, Colocações, frasemas, Pragmatemas (Braga: Centro de Estudos Humanísticos - Universidade do Minho). Tese de doutoramento dispoñíbel en http://repositorium.sdum. uminho.pt/bitstream/1822/4573/1/A_Unidade_Lexicografica.pdf. 
Krieger, Maria da Graça / Finatto, Maria José Bocorny (2004): Introdução à Terminologia. Teoria e Prática (São Paulo: Contexto).

Lanciani, Giulia (1977): Il canzoniere di Fernan Velho (L'Aquila: Japadre).

Lerat, Pierre (1997): Las lenguas especializadas (Barcelona: Ariel).

López Viñas, Xoán / Lourenço Módia, Cilha / Moreda Leirado, Marisa (2011²) [2010]: Gramática práctica da lingua galega. Comunicación e expresión (A Coruña: Baía Edicións).

Lorenzo, Ramón (1977): La traducción gallega de la Crónica General y de la Crónica de Castilla. II. Glosario (Ourense: Instituto de Estudios Orensanos "Padre Feijoo").

Lorenzo Gradín, Pilar (2008): Cantigas de Don Afonso Lopez de Baian (Alessandria: Edizioni dell'Orso).

Lorenzo Gradín, Pilar / Marcenaro, Simone (2011): Il canzoniere del trovatore Roi Queimado (Alessandria: Edizioni dell'Orso).

$L P=$ Brea, Mercedes (coord.) (1996): Lírica profana galego-portuguesa. 2 vols . (Santiago de Compostela: Xunta de Galicia / Centro Ramón Piñeiro para a Investigación en Humanidades).

$L T=$ Lorenzo Gradín, Pilar / Souto Cabo, José António (coord.) (2001): Livro de Tristan e Livro de Merlin. Estudio, edición, notas e glosario (Santiago de Compostela: Xunta de Galicia / Centro Ramón Piñeiro para a Investigación en Humanidades).

Lyons, J. (1980): Semántica (Barcelona: Teide).

Magne, Augusto (ed.) (1944): A Demanda do Santo Graal. Vol. III: Glossário (Rio de Janeiro: Imprensa Nacional).

Martínez de Sousa, José (1995): Diccionario de Lexicografia práctica (VOX) (Barcelona: BIBLIOGRAF).

Martínez de Sousa, José (2003): “La forma gráfica de los diccionarios”. Edición dixital dispoñíbel en http://www.martinezdesousa.net/formadiccio.pdf [Última consulta: 04.11.2011].

Martínez de Sousa, José (2009): Manual básico de lexicografía (Gijón: Trea).

Martínez Lema, Paulo (2008): “Un corpus para o estudo do galego medieval: o TMILG (Tesouro Medieval Informatizado da Lingua Galega)", en González Seoane, E. / Santamarina, A. / Varela Barreiro, X. (eds.), A lexicografía galega 
moderna: recursos e perspectivas (Santiago de Compostela: Instituto da Lingua Galega / Consello da Cultura Galega).

Martínez Pereiro, Carlos Paulo (ed.) (1992): As cantigas de Fernan Paez de Tamalancos. Edición crítica con introdución, notas e glosário (Santiago de Compostela: Edicións Laiovento).

Mettmann, Walter (ed.) (1972): Cantigas de Santa Maria. Vol. IV: Glossário (Coimbra: Universidade de Coimbra).

Michaëlis de Vasconcelos, Carolina (1920): "Glossário do Cancioneiro de Ajuda", Revista Lusitana XXIII, 1:4, 1-95.

$M S=$ Pensado Tomé, José Luís (ed.) (1958): Miragres de Santiago. Versión gallega del códice latino del siglo XII atribuido al papa Calisto I. Anexo LXVIII da Revista de Filología Española (Madrid: CSIC).

Nunes, José Joaquim (1973) [1928]: Cantigas de Amigo dos Trovadores GalegoPortugueses. Vol. III: Comentario, Variantes e Glossário, 575-704 (Lisboa: Centro do Livro Brasileiro).

$O L D=$ Oxford University Press (1968): Oxford Latin Dictionary (Oxford: Clarendon Press).

Peirce, Charles S. (1931-58): Collected Papers of Charles Sanders Peirce. Ed. by Hartshorne / Weiss (Cambridge, MA: Harvard University Press).

Pichel, Ricardo / Varela Barreiro, Xavier (2009): “O corpus do galego medieval: Tesouro Medieval Informatizado da Lingua Galega (TMILG)", en Enrique-Arias, A. (ed.): Diacronía en las lenguas iberorrománicas: nuevas aportaciones desde la lingüistica de corpus, 195-215 (Madrid / Frankfurt am Main: Iberoamericana / Vervuert).

Porto Dapena, José-Álvaro (2002): Manual de técnica lexicográfica (Madrid: Arco/ Libros).

Rey-Debove, Josette (1971): Étude linguistique et sémiotique des dictionaires français contemporains (The Hague: Mouton).

Sánchez Rei, Xosé Manuel (2005a): “Trazos xerais da tradición gramatical galega”, Revista Galega de Filoloxía 6, 93-121.

Simões, Manuel (1991): Il Canzoniere di D. Pedro, Conte di Barcelos. Ed. critica, con introduzione, note e glossario (L'Aquila: Japadre).

Tato Fontaíña, Laura (2007): O Cancioneiro de Pero Mendiz da Fonseca (Santiago de Compostela: Centro Ramón Piñeiro para a Investigación en Humanidades). 
Tavani, Giuseppe (1992): A poesía de Airas Nunez (Vigo: Galaxia).

TLFi $(2005)=$ Trésor de la Langue Française informatisé (Paris: CNRS Éditions). Dispoñíbel en http://atilf.atilf.fr/ e http://www. cnrtl.fr/etymologie/ [Última consulta 04.11.2011].

TMILG = Varela Barreiro, Xavier (dir.) (1993-): Tesouro Medieval Informatizado da Lingua Galega (Santiago de Compostela: ILG / USC).

Varela Barreiro, Xavier (2010): "Un novo glosario do Cancioneiro da Ajuda. A microestrutura das entradas verbais”, Estudos de Lingüística Galega 2, 141-171. Dispoñíbel en http://dx.doi.org/10.3309/1989-578X-10-7.

Xavier, Maria Francisca / Mateus, Maria Helena (orgs.) (1990/1992): Dicionário de Termos Lingüísticos. Vol. I (1992): Filología, Fonética, Fonología, Lingüística Histórica, Pragmática, Prosódia e Sociolingüistica. Vol. II (1992): Termos gerais, Morfología, Sintaxe, Semântica, Lexicología, Terminología e Psicolingüística (Lisbos: Cosmos). 
